"Encyclopædia Britannica". He was one of the first to be converted to Lavoisier's views on combustion, and did much to make known the advances made by French chemists. No great discovery is associated with his name, but his influence on the progress of chemistry was far reaching.

\section{Mr. G. C. Robson}

ZooLogisTs, especially those interested in the study of Mollusca, will learn with regret that $\mathrm{Mr}$. G. C. Robson has been compelled by ill-health to resign from the scientific staff of the British Museum (Natural History). Mr. Robson went to the Museum from Oxford in 1911 as an assistant in the Department of Zoology, and devoted his attention to the Mollusca, studying more especially their anatomy and ecology. Among his more important works were his account of parthenogenesis in the gasteropod Paludestrina and his contributions to the systematics of the Cephalopoda, especially the Octopoda, on which he wrote a monograph published in two volumes by the Museum in 1929 and 1931. His interest in the more general aspects of biology is shown in his book "The Species Problem" (1928) and in the recent volume "The Variation of Animals in Nature" (1936), in which he collaborated with Dr. O. W. Richards. In 1931 he was appointed one of the two deputy keepers in the Department of Zoology. Mr. Robson's work at the Museum has brought him into contact with malacologists all over the world, and his many friends will hope that freedom from official responsibility will bring about his restoration to health and to scientific activity.

\section{Messel Research Fellowship}

Dr. J. E. Harris, of Christ's College, Cambridge, has been awarded a Messel research fellowship in biology by the Royal Society as from January 1. Dr. Harris held a Commonwealth Fund fellowship at Columbia University and the Guggenheim School of Aeronautics in 1933-35, and has since been University demonstrator in zoology at Cambridge. He proposes to investigate how far current morphological views on the evolution of the fins of fish are substantiated by a study of the functions of these organs. From an analysis of the effect of the fins on an accurate model of the dogfish suspended in a wind tunnel, it has been found possible to draw fairly definite conclusions concerning the action of these fins on the static stability of the living fish. It seems likely that an extension of these methods to other types will throw light on the relationship between the form of the fins and the habits and possible course of evolution of the different groups. The work will be combined with a study of the neuromuscular mechanism and of the forces produced by actively moving fins, the methods available for such study having already proved adequate. It is hoped that time will also permit of the confirmation and interpretation of Dr. Harris's somewhat striking observation, that there exists in the nucleus of the unfertilized egg of echinoderms a physical polarity which can be demonstrated by observations on the rate of free fall of the nucleolus in the germinal vesicle. Dr. Harris will work at Cambridge and possibly also at the Tortugas Laboratory of the Carnegie Institution of Washington, and the Guggenheim School of Aeronautics, New York.

\section{The British Broadcasting Corporation}

THE present British Broadcasting Corporation was granted its first charter of incorporation on December 20, 1926, and a supplemental charter on August 14, 1931. The special Committee, which was set up by the Postmaster-General, has recently conducted an inquiry into the broadcasting service and has recommended that the service should continue to be developed and exploited to the best advantage and in the national interest. This action is very desirable on account of the widespread interest in broadcasting, as illustrated by the fact that more than seven and a half million persons in Great Britain and Northern Ireland now have licences to instal apparatus for the reception of broadcast programmes. Accordingly, the British Broadcasting Corporation will continue in being under a new charter which came into operation on January 1, 1937, the draft of which has recently been published by H.M. Stationery Office as Cmd. 5329 (4d. net). In this paper, the objects of the Corporation are described in some detail; briefly, they may be summarized as the development, exploitation and maintenance of a public utility service for broadcasting to the public by means of wireless telephony and television any matter of interest, which may be permitted within the terms of the licence and agreement between H.M. Postmaster-General and the B.B.C. The draft of this licence is also included in the White Paper referred to above. The charter outlines the organization of the Corporation by means of a chairman, vicechairman and body of governors, and the chief executive officer of the Corporation is the directorgeneral. The Corporation is authorized and em. powered to receive and administer the funds granted annually by the legislative for the objects in view, and provision is made for the submission of an annual report and statement of accounts. To the lay mind, it is satisfactory to note from this paper that the broadcasting service in Great Britain will continue to maintain its unrivalled reputation, controlled and yet not hampered by Government administration, free to develop and exploit to the full the technique of broadcasting by both sound and vision.

\section{Salvador Earthquake of December 20}

For its size, the small republic of Salvador, containing only 7,225 square miles, has been visited by great destructive earthquakes more frequently than any other country. During the nineteenth century, there were at least fifteen such earthquakes, and Montessus records the ruin of San Salvador eleven times between 1538 and 1854. San Vicente, a town of 26,000 inhabitants and lying about 35 miles to the east of San Salvador, has suffered from earthquakes several times during the last century, and was almost ruined by a violent shock on the morning of December 20. With one 